\title{
Bioprosthetic leaflet perforation associated with suture tails
}

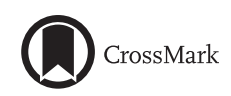

\author{
Mototsugu Tamaki, MD, Hideki Kitamura, MD, and Arishige Kimura, MD
}

From the Department of Cardiovascular Surgery, Nagoya Heart Center, Nagoya, Japan.

Disclosures: Authors have nothing to disclose with regard to commercial support.

Received for publication June 15, 2016; revisions received June 22, 2016; accepted for publication June 24, 2016; available ahead of print Aug 4, 2016.

Address for reprints: Hideki Kitamura, MD, 1-1-14 Sunadabashi, Higashi-ku, Nagoya, Aichi 461-0045, Japan

(E-mail: kitamura@heart-center.or.jp).

J Thorac Cardiovasc Surg 2016;152:1432-3

$0022-5223 / \$ 36.00$

Copyright (c 2016 by The American Association for Thoracic Surgery

http://dx.doi.org/10.1016/j.jtcvs.2016.07.012

Three years after aortic supra-annular valve replacement with a 21-mm Trifecta valve (St Jude Medical, Inc, St Paul, Minn), a 76-year-old man underwent reoperation for progressive paravalvular aortic regurgitation. The explanted valve contained a $1.5-\mathrm{mm}$ perforation at the midportion of the noncoronary cusp (Figure 1) and a 2-mm superficial abrasion at the mid portion of the left coronary cusp (Figure 2). Grossly, this perforation appeared to be in line with the 2-0 polyester braided suture tails (NESPOLEN; Alfresa, Inc, Osaka, Japan), and microscopically, there were no specific changes to the tissue in that area to suggest an etiology for the perforation. The abrasion also appeared to be in line with 1 suture tail. We and St Jude Medical Laboratory agreed that this perforation was caused by continuous trauma of the leaflet against the suture tails.

Trifecta has externally mounted pericardial leaflets around the stent, which provide excellent hemodynamic performance. ${ }^{1}$ As the leaflet expands over the stent posts during

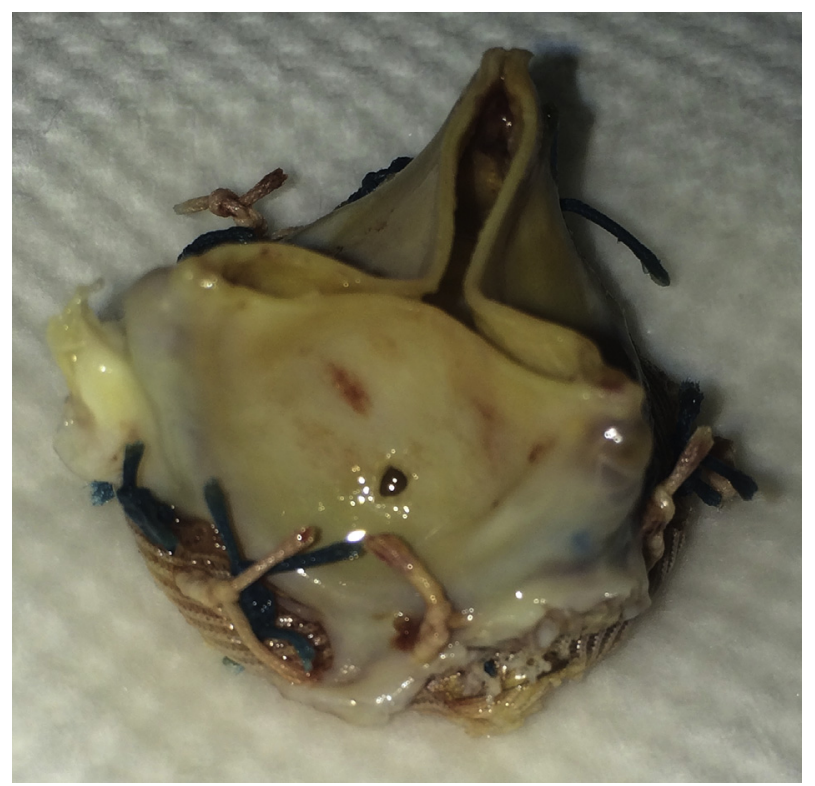

FIGURE 1. The explanted valve contains a $1.5-\mathrm{mm}$ perforation at the midportion of the noncoronary cusp, which appears to be in line with the suture tails.

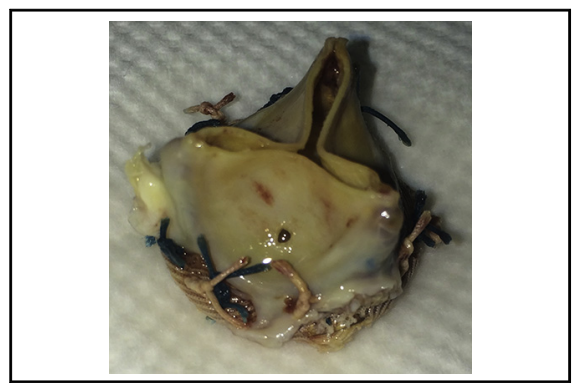

A perforation at the midportion of the cusp appears to be in line with suture tails.

\section{Central Message}

Externally mounted leaflets expand over the stent in systole. The tails of the sutures should be cut short to prevent repetitive trauma.

See Editorial Commentary page 1433.

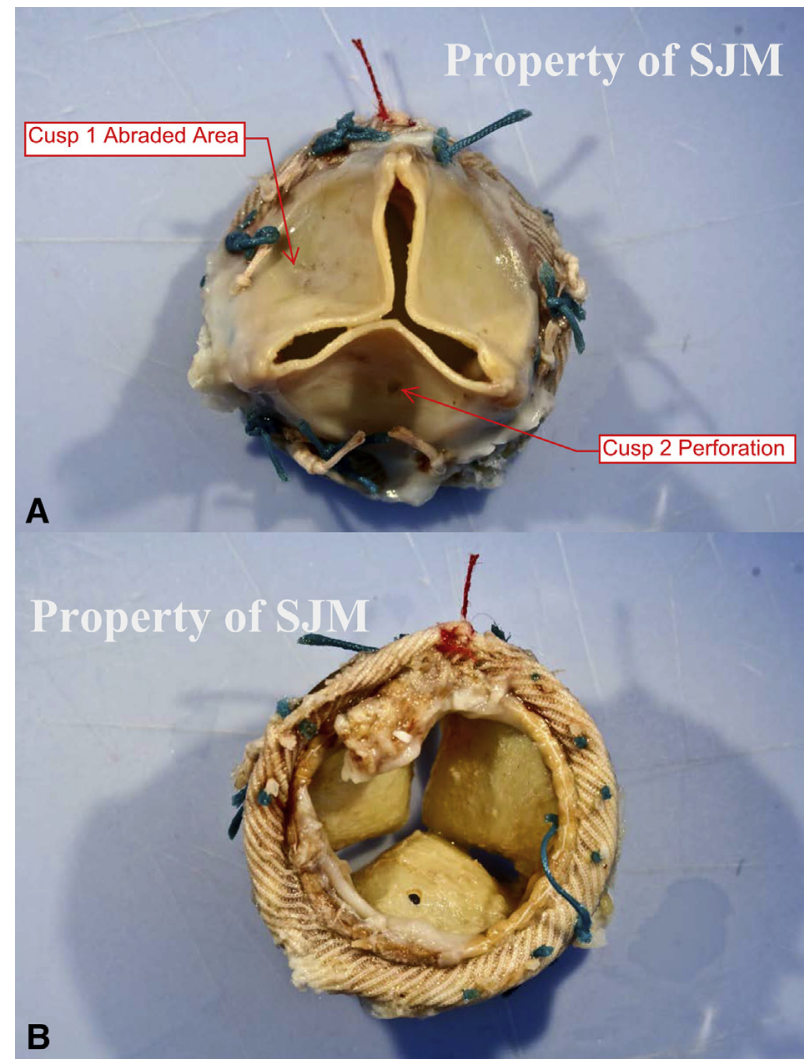

FIGURE 2. A, The explanted valve from the outflow view. Cusp 1 corresponds to the left coronary cusp. There is a 2-mm superficially abraded area. Cusp 2 corresponds to the noncoronary cusp, which contains a perforation in the midportion. B, The view from the inflow. There are no specific changes to the tissue of the valve to suggest an etiology for the perforation. SJM, St Jude Medical. (Printed with permission from St Jude Medical, Inc, St Paul, Minn.) 
the systolic phase, however, the leaflet easily tends to touch suture remnants, such as overknotted sutures or suture tails that are too long. ${ }^{2,3}$ Overknotted sutures should be avoided, and suture tails should be cut as short as possible, especially when implanting an externally mounted bioprosthesis.

This report was approved by the institutional ethics committee of Nagoya Heart Center. Written, informed consent was obtained from the patient.

\section{References}

1. Bach DS, Patel HJ, Kolias TJ, Deeb GM. Randomized comparison of exercise hae modynamics of Freestyle, Magna Ease and Trifecta bioprostheses after aortic valve replacement for severe aortic stenosis. Eur J Cardiothorac Surg. January 27, 2016 [Epub ahead of print].

2. Garcia-Valentin A, Castellá M, Josa M, Mulet J. Bioprosthetic leaflet perforation due to repetitive trauma by overknotted sutures. Eur J Cardiothorac Surg. 2006; 29:106.

3. Jones M, Rodríguez ER, Eidbo EE, Ferrans VJ. Cuspal perforations caused by long suture ends in implanted bioprosthetic valves. J Thorac Cardiovasc Surg. 1985;90:557-63.

\title{
EDITORIAL COMMENTARY
}

\section{The tail wagging the dog: Attention to detail in valvular surgery}

\author{
Vivek Rao, MD, PhD
}

\footnotetext{
From Cardiovascular Surgery, Peter Munk Cardiac Centre, Toronto General Hospital, Toronto, Ontario, Canada. Disclosures: Author has nothing to disclose with regard to commercial support.

Received for publication July 5, 2016; accepted for publication July 6, 2016; available ahead of print Aug 24, 2016.

Address for reprints: Vivek Rao, MD, PhD, Cardiovascular Surgery, Peter Munk Cardiac Centre, Toronto General Hospital, 200 Elizabeth St, Toronto, Ontario, Canada M5G2C4 (E-mail: vivek.rao@uhn.ca). J Thorac Cardiovasc Surg 2016;152:1433-4 $0022-5223 / \$ 36.00$

Copyright (C 2016 by The American Association for Thoracic Surgery http://dx.doi.org/10.1016/j.jtcvs.2016.07.041
}

Successful valve surgery requires exquisite attention to detail at all phases of the operation. In aortic valve surgery, careful debridement of the calcified annulus and appropriate sizing of the aortic root are basic techniques taught to all cardiovascular surgical trainees. Careful placement of annular sutures is then demonstrated to avoid paravalvular leaks. Attention to the aortotomy is important while seating the valve to avoid tearing of the often-friable aorta. Next, appropriate tension while tying the annular sutures will avoid "pulling" through the native tissue while at the same time avoiding suture breakage or worse, a loose knot leading to an insecure valve. In this issue of the Journal, Dr Tamaki and colleagues ${ }^{1}$ turn our attention to an often-overlooked component of the operation: suture cutting.

The very convincing figures and the early failure of a Trifecta (St. Jude Medical, Minneapolis, Minn) bioprosthesis point to repetitive trauma from an adjacent suture tail. A careful review of Figure 1 in the article of Tamaki and colleagues will demonstrate what we would normally consider an inappropriately long suture tail. Our trainees are instructed to cut sutures carefully at the level of the knot and to avoid tying more than 5 or 6 throws on any given suture to avoid a potentially dangerous suture tail. This case

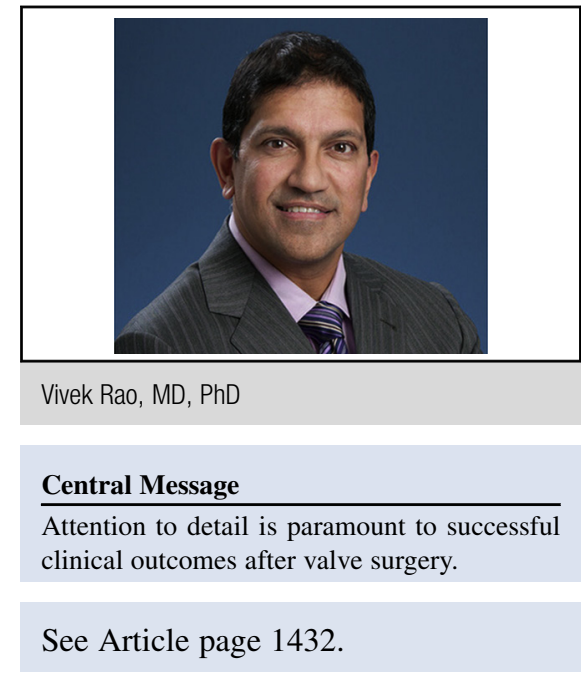

report and several personal anecdotes lends evidence to the prevailing theory that inappropriately long suture tails (either as the result of excessive throws or sutures cut too long) can cause injury. A similar phenomenon was observed when PROLENE sutures (Ethicon, Somerville, NJ) were used to repair degenerative mitral valves (Marc Gillinov, personal communication). A long tail (necessitated by the $>8$ throws needed when tying PROLENE) caused repetitive injury to a previously normal anterior mitral leaflet leading to perforation.

The authors also allude to the fact that externally mounted bioprosthesis such as the Trifecta or the Mitroflow (LivaNova; London, United Kingdom) are more prone to this form of injury as the cusps open wider during systole and are therefore more likely to come into contact with annular 